\title{
Strategies for school buildings refurbishment in Portuguese climate
}

\author{
Francisca Cavaleiro Barbosa ${ }^{1, *}$, Vasco Peixoto de Freitas ${ }^{1}$, and Manuela Almeida ${ }^{2}$ \\ ${ }^{1}$ Construct-LFC, Faculty of Engineering, University of Porto, Portugal \\ ${ }^{2}$ CTAC, Department of Civil Engineering, School of Engineering, University of Minho, Portugal
}

\begin{abstract}
Portuguese school buildings are generally characterized by an in-service thermal discomfort, due to the poor envelope thermal properties and the lack of resources for paying energy consumption. Most Portuguese schools are free-running buildings with a natural ventilation strategy. Hundreds of high and basic schools have not been refurbished and still have problems or anomalies and inadequate in-service conditions and need to be rehabilitated in the near future. There will be, therefore, an opportunity to apply the acquired knowledge of comfort, habits, energy consumption and costs that have been studied since the last refurbishments (2008). This work studies the Portuguese Brandão schools model (from the '70s), including about 100 non-refurbished basic schools. A prototype classroom was prepared in a Brandão school, in Porto. The in situ experimental campaign consisted of temperature, relative humidity, $\mathrm{CO}_{2}$ concentration and energy consumption measurements. The main tasks of this work are: (1) the validation of an advanced hygrothermal model with experimental measurements before and after the prototype refurbishment; (2) development of a sensitivity study in order to choose the best refurbishment and heating strategies for these buildings, regarding their typology, the local climate features and the actual capacity to support the operating costs; (3) assessment of the roof insulation thickness in Brandão schools; (4) quantification of discomfort indicators.
\end{abstract}

\section{Introduction}

\subsection{Background}

The physical environment affects teaching and learning, and this justifies the investment in comfort and indoor air quality (IAQ). The low ventilation rates in classrooms reduce students' attention and vigilance and negatively affecting memory and concentration $[1,2]$.

Portuguese school buildings are generally characterized by an in-service thermal discomfort, due to the poor envelope thermal properties and the lack of resources for paying energy consumption. Most Portuguese schools are free-running buildings with a natural ventilation strategy [3]. For that reason, the highly relevant international studies on schools' energy consumption and potential savings mentioned in the bibliography [4-8] do not reflect the Portuguese reality.

Portugal, in southwestern Europe, is mostly defined by a temperate Mediterranean climate, with rainy winters and dry and hot summers (although it may present a considerable climatic diversity). It is possible to find monthly average minimum temperatures of $0.3^{\circ} \mathrm{C}$ (Bragança), $5.0^{\circ} \mathrm{C}$ (Porto) and $8.1^{\circ} \mathrm{C}$ (Lisbon) in January and monthly average maximum temperatures of $28.5^{\circ} \mathrm{C}$ (Bragança), $25.0^{\circ} \mathrm{C}$ (Porto) and $27.8^{\circ} \mathrm{C}$ (Lisbon) in August [9]. The Koppen-Geiger Classification system classifies the Portuguese territory as mainly temperate climate type C, with two variations, Csa and Csb [9]. It is also possible to find the sub-type BSk in a small region of the Baixo Alentejo.

Portugal's climatic pattern is similar to some other southern European countries, namely Spain, southern France, southwest Italy and Greece. However, even with similar climatic conditions, conclusions about energy performance, thermal comfort and IAQ in schools are not the same for each location once the local preferences have an important role [10]. In Portugal, the cultural habits, the non-insulated buildings envelope and the economic restrictions lead to an absence of heating and cooling strategies, which is not expected to change in the near future. Previous studies carried out in Portuguese schools do not indicate any significant differences between the average profile of electricity consumption for schools with or without a heating system, suggesting their reduced use [11].

In the past, there were some typified projects for the refurbishment of school buildings replicated throughout the country, without the necessary adaptations to the particular climatic features. Likewise, the replication of the same solution in distinct refurbishment projects will have different repercussions on the hygrothermal environment inside the classrooms.

\footnotetext{
* Corresponding author: francisca.barbosa@,fe.up.pt
} 
In the recent past (from 2007 to 2011), 175 Portuguese schools were refurbished. The investment reached 2400 million euros and focused mainly on high schools. Despite the important investment and the high quality of the intervention, these refurbishments have not fully considered the economic reality. For the future, the challenge will be the refurbishment of the remaining schools taking into account their typology, the climate features and the actual capacity to support the operating costs.

\subsection{Main goals}

This work aims to contribute to the refurbishment of school buildings in free-running conditions or with intermittent heating strategies, considering the temperate Mediterranean climate features and the actual capacity to support the operating costs.

In order to address the previously proposed main goals, the following tools were developed/implemented:

(1) Preparation of a prototype in a Brandão classroom in Porto (refurbishment design project and implementation).

(2) Experimental measurement of hygrothermal performance and energy consumption (EC) of the Brandão classroom prototype in Porto, before and after the refurbishment.

(3) Validation of an advanced hygrothermal model (Wufi Plus) that reproduces the in situ conditions and allows the study of the other Portuguese Brandão buildings.

(4) Sensitivity analysis through a numerical hygrothermal model that studies different envelope refurbishment strategies (roof insulation, walls insulation, floor insulation, windows and solar protection, ventilation and heating) in Portuguese cities with distinct climatic features and heating strategies ( $3 \mathrm{~h}$ heating, $5 \mathrm{~h}$ heating and $9 \mathrm{~h}$ heating).

The refurbishment strategy for Brandão schools resulted from the sensitivity study, with the main goal of reducing occupant thermal discomfort, without compromising IAQ and the present low energy consumption.

In order to suggest appropriate refurbishment strategies for the situation of these Portuguese buildings, the thermal discomfort was quantified (by discomfort indicators) and the associated energy consumption.

Two main approaches were followed:

- A "minimizing discomfort" approach, considering free-running conditions or intermittent heating strategies. In this case, the comfort performance (temperature $-\mathrm{T}-$ and relative humidity - RH), the IAQ performance and the EC (predictably low in this approach, respecting the present strategy in these schools with low EC) were the decision variables to be considered in the decision process.

- A "comfort" approach, considering a regular heating strategy (during the occupation period), in which the most important decision variable was EC, once the comfort requirements were almost fulfilled during the occupation period. The quantification of EC enabled the comparison and selection of the best rehabilitation solutions, to ensure comfort conditions with a controlled and known increase in operating costs.

\section{Methodology}

\subsection{Case study and prototype refurbishment}

The object of this study is the Portuguese Brandão model, including 100 basic schools replicated throughout the country in the 70s [12]. This is a pavilion type project, composed by quadrangular single floor blocks of classrooms with a central courtyard (Figure 1) [13]. Classrooms can be accessed around the building (outdoor circulation) or through the neighboring classrooms (indoor circulation), once they are clustered by a common circulation zone.

It is assumed that these non-refurbished schools have very low comfort and inadequate hygrothermal conditions and will possibly require some interventions in the near future. It is thus important to define some strategies for the refurbishment of these basic schools, considering passive low-cost interventions and the appropriate use of affordable intermittent heating strategies.

A prototype west-sided classroom (Figure 2) has been studied in a Brandão school in Porto.

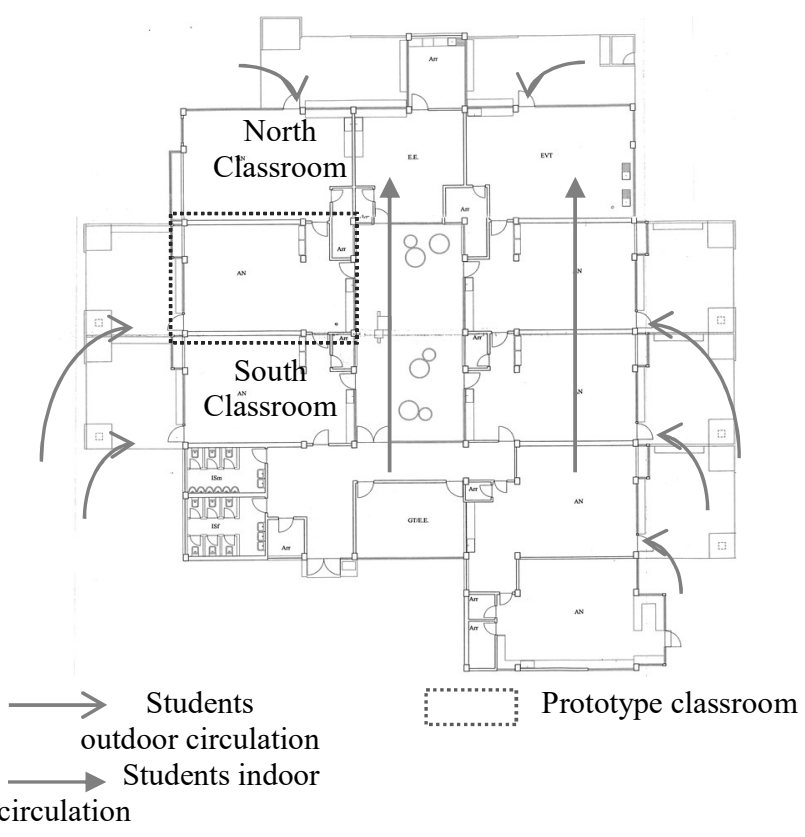

Fig. 1. Classrooms block.

The main goal of the prototype construction is the assessment of the classroom behaviour before and after the refurbishment and the validation of an advanced hygrothermal numerical model. This refurbishment intended to minimize the discomfort in this classroom, regarding the typical in-service conditions in this kind of schools.

The implementation of a partition wall and the upgrade of the envelope allowed the introduction of heating strategies and the improvement of the hygrothermal behaviour. The partition wall also allowed the control of the ventilation in order to ensure IAQ. The 
following interventions were implemented (Figure 2): electric heating system; partition wall between the classroom and the circulation zone; ventilation system with naturally filtered inflow and forced airflow to the circulation zone; exterior blinds; roof insulation.
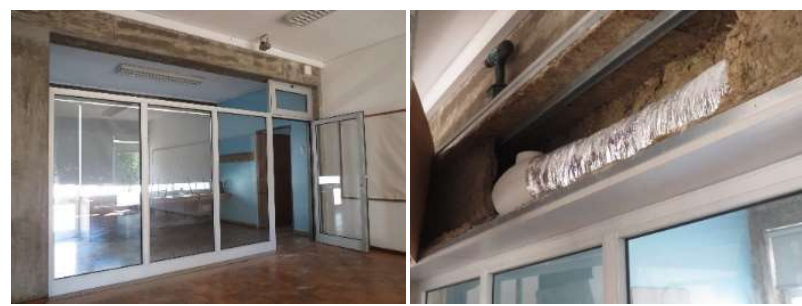

(a)

(b)
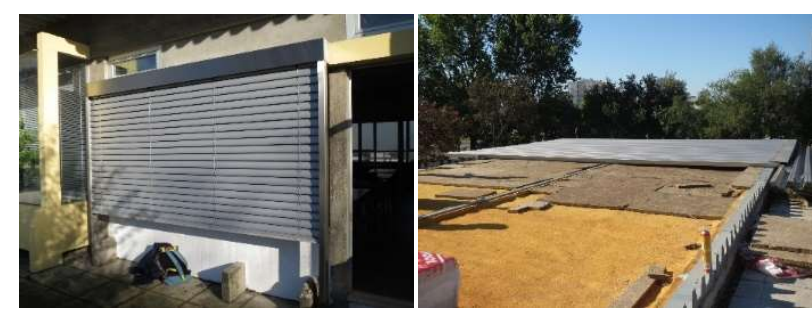

(c)

(d)

Fig. 2. Prototype interventions: (a) partition wall; (b) ventilation system; (c) exterior blinds; (d) roof insulation.

\subsection{Experimental measurement}

The experimental campaign included the continuous measurement of T, $\mathrm{RH}, \mathrm{CO}_{2}$ concentration $\left(\mathrm{CO}_{2}\right)$ and $\mathrm{EC}$.

The hygrothermal monitoring was done by a Wireless Aptinov system composed by a $3 \mathrm{G}$ router with GSM, a GW357-2 gateway, 11 Aptinov WLS-05 dataloggers for T and $\mathrm{RH}$ and 2 Telaire 7001 sensors coupled to 2 Aptinov WLS-07 dataloggers for $\mathrm{CO}_{2}$. The communication between the sensors and the system was performed through electromagnetic transmission of radio waves.

The EC monitoring was done by a Wireless Cloogy Smart Living connected to a $3 \mathrm{G}$ router with GSM, a Cloogy Hub concentration, 2 mini-transmitters coupled to ammeter clamps for lighting and ventilation monitoring and 4 smart plugs for the equipment connected to electrical plugs.

Both monitoring systems were a long-distance acquisition of data systems. In addition, the energy consumption system was linked to a web management platform that facilitated data real-time processing.

\subsection{Wufi Plus model validation}

The calibration tools were the Wufi Plus software (to the model simulation), the climatic data (that represent the real climatic conditions during experimental measurements), the experimental measurements (to compare with the simulation results) and the prototype refurbishment (to control the envelope conditions and the ventilation rate and also to perform different conditions to strongly validate the model).
For the validation of the Brandão schools model, some calibration tests were done by comparing the indoor environmental measurements of $\mathrm{T}$ obtained from in situ monitoring with simulation results.

The validation was divided into three steps: (1) before the intervention in free-running conditions; (2) after the intervention in free-running conditions; (3) after the intervention with three heating strategies in a weekly schedule calendar.

Through a detailed weekly analysis (Figure 3 - before refurbishment; Figure 4 - after refurbishment), it is possible to observe that the occurrence of higher gaps between measured and simulated data is during the heating weeks.

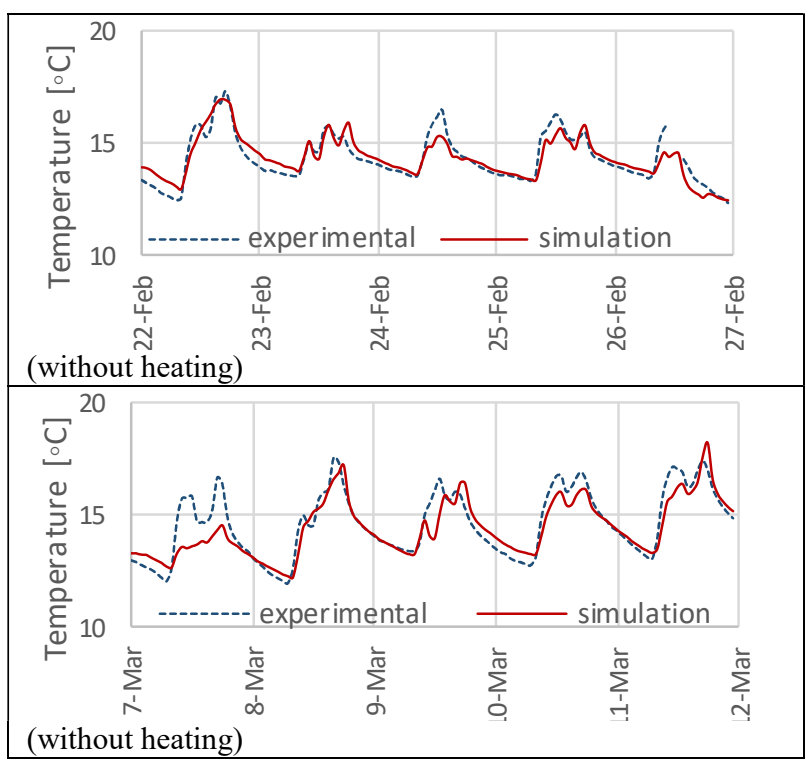

Fig. 3. Weekly experimental and simulated development of T before refurbishment.

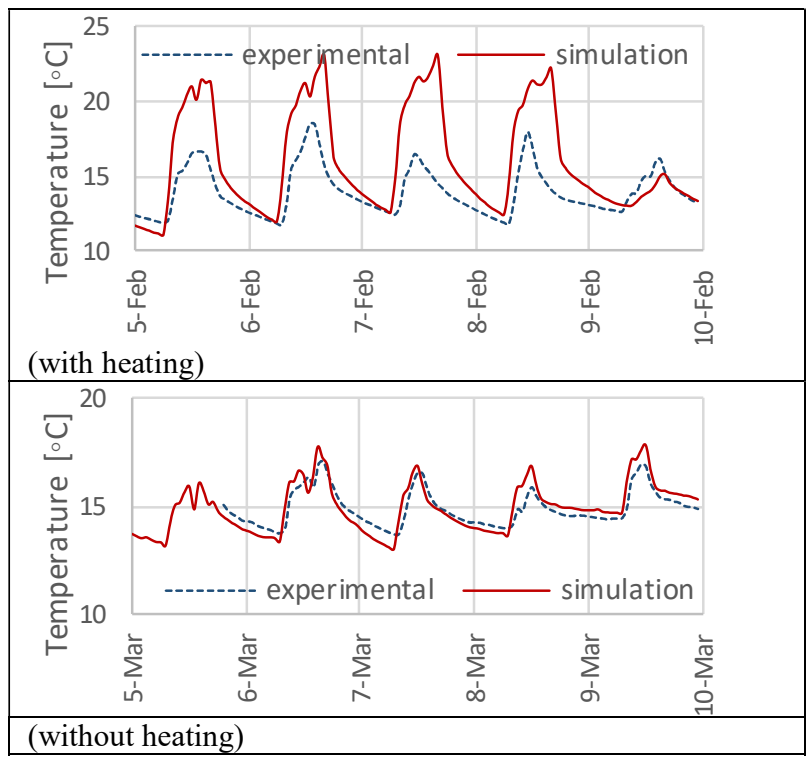

Fig. 4. Weekly experimental and simulated development of T after refurbishment. 
Figure 5 represents a statistical analysis of the $T$ differences inside the prototype classroom for three distinct situations after refurbishment: (a) free-running condition, without heating; (b) 3 heating hours/day in early morning; (c) 10 heating hours/day. In fact, Wufi considers an efficient heating system uniformly distributed in the classroom and also an instantaneously heating strategy that does not correspond to the reality in the prototype. Furthermore, the measured in-service conditions reveal an important temperature stratification in different classroom locations that justifies the differences between experimental data and simulation.

The $\mathrm{R}^{2}$ statistical parameter describes the correlation between measured and simulated values. After refurbishment, the $\mathrm{R}^{2}$ for the whole period and for the occupation period are 0.92 and 0.80 respectively, which fulfils the requirement of 0.75 [14]. The $\mathrm{R}^{2}$ indicates a good correlation between measurements and simulation results.

Despite the limitations previously referred, the advanced hygrothermal model was strongly validated for $\mathrm{T}$ and the statistical analysis proved its strength.

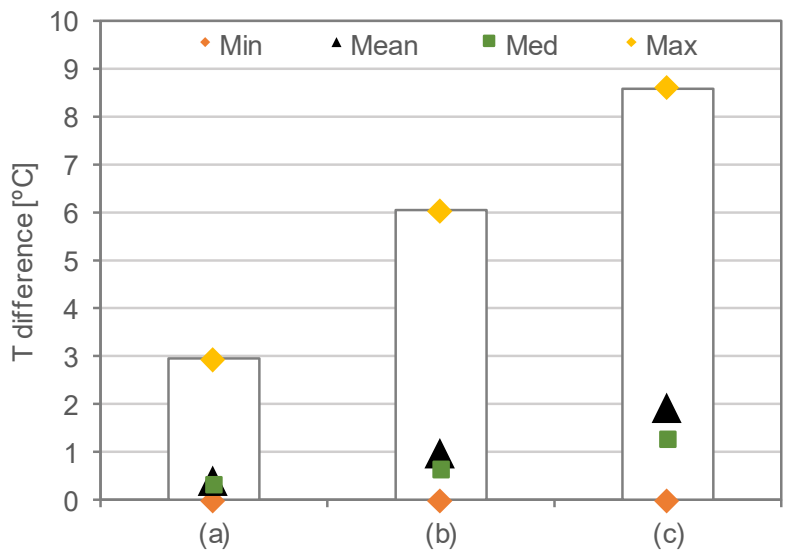

Fig. 5. Statistical analysis of $T$ differences after refurbishment for each heating strategy.

\subsection{Discomfort indicators}

The discomfort indicators quantify how long occupants are experiencing discomfort (above or below reference) and the effort required to achieve reference comfort conditions. The indicators of discomfort (for the period of occupation) compare pre-existing discomfort and discomfort after refurbishment.

The discomfort index for winter $\left(\mathrm{DI}_{\mathrm{w}, \mathrm{b}}\right)$ is the sum of positive differences between comfort temperature $\left(20^{\circ} \mathrm{C}\right)$ and real temperature, in ${ }^{\circ} \mathrm{C}$.hour (equation 1). When the reference temperature of comfort is $20^{\circ} \mathrm{C}, \mathrm{DI}_{\mathrm{w}, \mathrm{b}}$ is classified as $\mathrm{DI}_{\mathrm{w}, 20 \text {. }}$

$$
D I_{w, b}=\sum_{t_{i}}^{t_{n}}\left(\theta_{b}-\theta_{i}\right), \text { when } \theta_{\mathrm{i}}<\theta_{\mathrm{b}}
$$

where $\mathrm{DI}_{\mathrm{w}, \mathrm{b}}$ is the discomfort index in ${ }^{\circ} \mathrm{C}$.hour, $\theta_{\mathrm{b}}$ is the reference temperature of comfort $\left(20^{\circ} \mathrm{C}\right)$ and $\theta_{i}$ is the experimental hourly temperature in each period $t_{i}$.
The discomfort percentage of time $\left(\% \mathrm{DT}_{\mathrm{b}}\right)$ represents the proportion of the discomfort periods during the analysed occupation period (equation 2).

$$
\% T D_{b}=\frac{\sum t_{\text {idiscomfort }}}{\sum t_{\text {ioccupation }}}
$$

\subsection{Sensitivity study}

The validated numerical simulation model in Wufi Plus is the main tool for quantifying comfort and energy performance of the Brandão schools under different rehabilitation scenarios. Three main groups of variables were identified: construction elements (roof, walls and floor insulation, windows and solar protections), technical systems (heating and ventilation strategy) and building features (climatic conditions and building orientation).

\begin{tabular}{|c|c|}
\hline $\mathbf{L}$ & $\begin{array}{l}\text { Location } \\
\text { Bragança } \\
\text { Braga } \\
\text { Porto } \\
\text { Lisboa } \\
\text { Évora }\end{array}$ \\
\hline $\begin{array}{l}\mathbf{O} \\
\mathrm{N} \\
\mathrm{S} \\
\mathrm{E} \\
\mathrm{W}\end{array}$ & $\begin{array}{l}\text { Orientation } \\
\text { North } \\
\text { South } \\
\text { East } \\
\text { West }\end{array}$ \\
\hline $\begin{array}{l}\text { R } \\
\text { R0 } \\
\text { R5 } \\
\text { R7 } \\
\text { R10 }\end{array}$ & $\begin{array}{l}\text { Roof insulation } \\
\text { Mineral Wool }(\lambda=0.034 \mathrm{~W} /(\mathrm{m} . \mathrm{K})) \\
0 \mathrm{~cm}\left(\mathrm{U}_{\text {roof }}=3.17 \mathrm{~W} /\left(\mathrm{m}^{2} .{ }^{\circ} \mathrm{C}\right)\right) \\
5 \mathrm{~cm}\left(\mathrm{U}_{\text {roof }}=0.56 \mathrm{~W} /\left(\mathrm{m}^{2} .{ }^{\circ} \mathrm{C}\right)\right) \\
7 \mathrm{~cm}\left(\mathrm{U}_{\text {roof }}=0.42 \mathrm{~W} /\left(\mathrm{m}^{2} .{ }^{\circ} \mathrm{C}\right)\right) \\
10 \mathrm{~cm}\left(\mathrm{U}_{\text {roof }}=0.31 \mathrm{~W} /\left(\mathrm{m}^{2} .{ }^{\circ} \mathrm{C}\right)\right)\end{array}$ \\
\hline $\begin{array}{l}\text { W } \\
\text { W0 } \\
\text { W5 } \\
\text { W8 }\end{array}$ & $\begin{array}{l}\text { Wall insulation } \\
\text { Mineral Wool }(\lambda=0.034 \mathrm{~W} /(\mathrm{m} . \mathrm{K})) \\
0 \mathrm{~cm} \\
5 \mathrm{~cm} \\
8 \mathrm{~cm}\end{array}$ \\
\hline $\begin{array}{l}\text { F0 } \\
\text { F3 }\end{array}$ & $\begin{array}{l}\text { Floor insulation } \\
X P S(\lambda=0.035 \mathrm{~W} /(m . K)) \\
0 \mathrm{~cm} \\
3 \mathrm{~cm}\end{array}$ \\
\hline $\begin{array}{l}\text { W_SP }(*) \\
0 \_0 \\
0 \_1 \\
1 \_1 \\
2 \_1\end{array}$ & $\begin{array}{l}\text { Windows and solar protection } \\
\text { SG without SP } \\
\text { SG with SP } \\
\text { DG1 with SP } \\
\text { DG2 with SP }\end{array}$ \\
\hline $\begin{array}{ll}V \\
\text { V1 } \\
\text { V2 } \\
\text { V3 }\end{array}$ & $\begin{array}{l}\text { Ventilation } \\
2.0 \mathrm{~h}^{-1}\left(260 \mathrm{~m}^{3} / \mathrm{h}\right) \\
3.0 \mathrm{~h}^{-1}\left(400 \mathrm{~m}^{3} / \mathrm{h}\right) \\
3.8 \mathrm{~h}^{-1}\left(500 \mathrm{~m}^{3} / \mathrm{h}\right)\end{array}$ \\
\hline $\begin{array}{l}\mathbf{H} \\
\mathrm{H} 1 \\
\mathrm{H} 2 \\
\mathrm{H} 3\end{array}$ & $\begin{array}{l}\text { Heating } \\
3 \mathrm{~h} \\
5 \mathrm{~h} \\
\text { energy for comfort }(9 \mathrm{~h})\end{array}$ \\
\hline
\end{tabular}
Figure 6 presents the three groups of variables.

(*) Legend: $\mathrm{SG}$ - Single glazing $\mathrm{U}=6.2 \mathrm{~W} /\left(\mathrm{m}^{2} . \mathrm{K}\right)$ and $\mathrm{g}=0.85$; DG1 Double glazing $\mathrm{U}=3.3 \mathrm{~W} /\left(\mathrm{m}^{2} . \mathrm{K}\right)$ and $\mathrm{g}=0.75$; DG2 - Double glazing $\mathrm{U}=2.8 \mathrm{~W} /\left(\mathrm{m}^{2} . \mathrm{K}\right)$ and $\mathrm{g}=0.42 ; \mathrm{SP}-$ Solar protection

Fig. 6. Groups of variables for sensitivity study. 


\section{Discussion of results}

\subsection{Simulation results for Porto}

The results here presented were obtained by simulation from Wufi Plus model with TRY-Porto climatic data [15]. In this paper, the discussion is focused on the optimization of roof insulation thickness in Brandão schools for different heating strategies (H1, H2 and H3). The insulation thicknesses (R0, R5, R7 and R10) are compared considering the existing envelope scenario (without walls insulation - W0 and without floor insulation - F0) and for W1SP1 window solution (double glazing with exterior solar protection).

Figure 7 presents the discomfort indicators for a Brandão school in Porto.

For the three orientations (West, South and North) the most important share of winter discomfort reduction was obtained from the first increment $(\Delta(\mathrm{R} 0-\mathrm{R} 5))$ of the insulation thickness. This conclusion was confirmed for $3 \mathrm{~h}, 5 \mathrm{~h}$ and 9 heating hours. The higher the reduction in ${ }^{\circ} \mathrm{C}$.hour, the lower the heating strategy was, but in percentage, the reduction was about $25 \%$ in $\mathrm{H} 1,30 \%$ in $\mathrm{H} 2$ and $45 \%$ in $\mathrm{H} 3$ heating strategy.

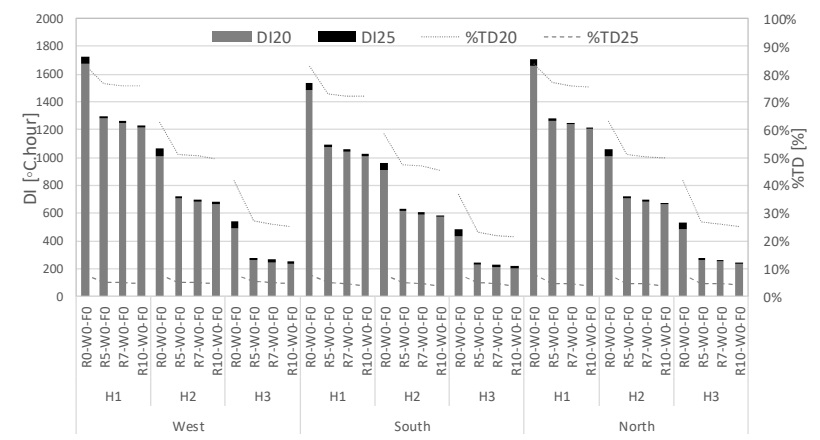

Fig. 7. $\mathrm{DI}_{20}$ and $\% \mathrm{TD}_{20}$ in a Brandão school in Porto for different roof insulation thicknesses.

Figure 8 presents the energy consumption (EC) for a Brandão school in Porto, for the previously referred roof insulation thicknesses.

The most important EC reduction was verified from the $0 \mathrm{~cm}$ solution (R0) to the $5 \mathrm{~cm}$ solution (R5), whatever the building orientation was. However, the additional investment in strong insulation thicknesses did not have an important reduction of the discomfort.

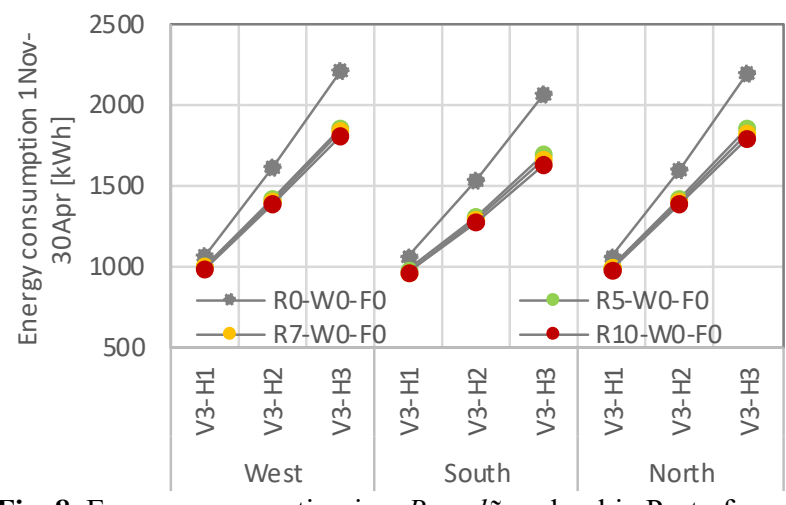

Fig. 8. Energy consumption in a Brandão school in Porto for different roof insulation thicknesses.
Figure 9 shows the association between the Winter thermal discomfort and the EC for the three main orientations. For $\mathrm{H} 1$ heating strategy, there was an important reduction of $\mathrm{DI}_{20}$ from $\mathrm{R} 0$ to $\mathrm{R} 5\left(400{ }^{\circ} \mathrm{C}\right.$.hour in a West sided-school) but when the heating strategy increases, the $\mathrm{DI}_{20}$ reduction has a lower relevance (230 ${ }^{\circ} \mathrm{C}$.hour) and the reduction of EC increases (from 65 to $340 \mathrm{kWh}$ ). The higher the heating strategy was, the more relevant was the EC reduction associated with the roof insulation thickness increase. The investment in stronger insulation thicknesses (R7 and R10) does not show a relevant reduction in $\mathrm{DI}_{20}$ or $\mathrm{EC}$.
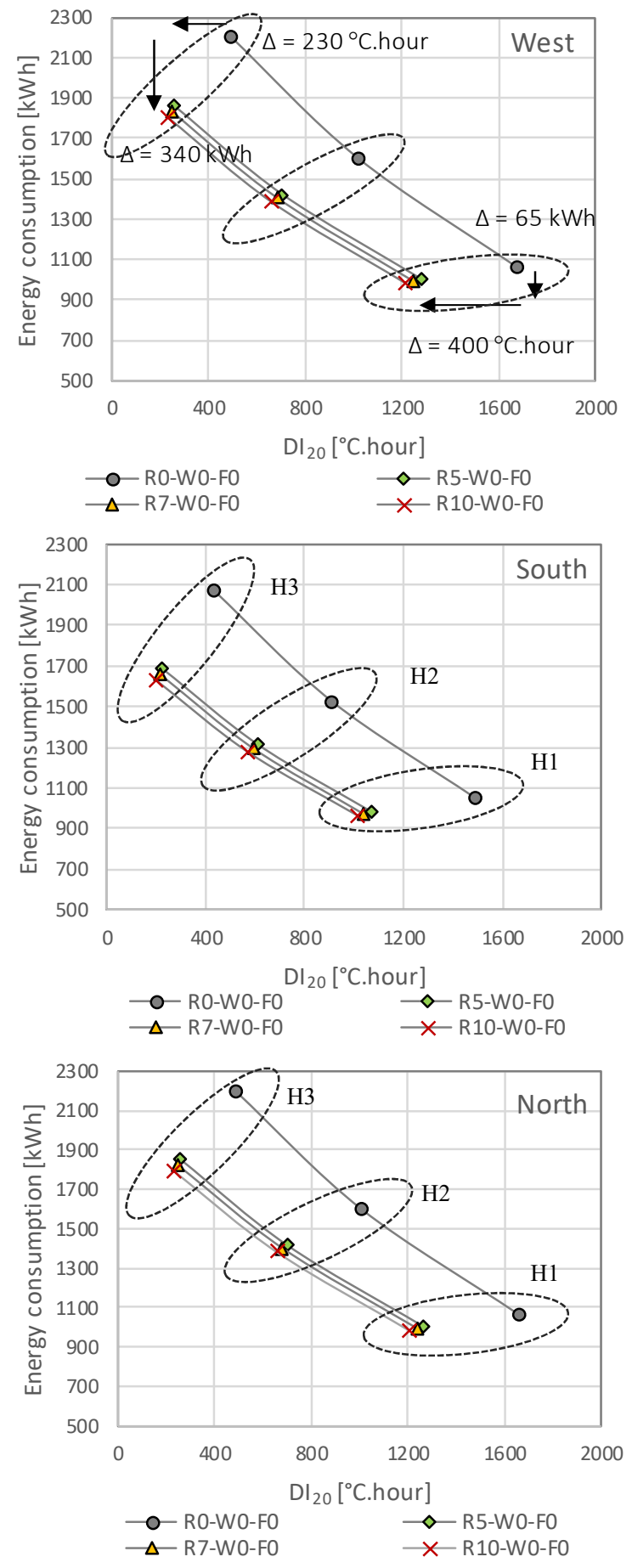

Fig. 9. Association between the winter thermal discomfort and the energy consumption in a Brandão school in Porto for different roof insulation thicknesses. 


\subsection{Simulation results for Portuguese cities}

The results here presented were obtained by simulation from Wufi Plus model with IPMA climatic data (Portuguese Institute for Sea and Atmosphere). In this chapter, the roof insulation thickness optimization in Brandão schools for different heating strategies (H1, H2 and H3) are discussed for different Portuguese cities with distinct climatic conditions. The insulation thicknesses (R0, R5 and R7) are compared considering the preexisting envelope scenario (without walls insulation - W0 and without $\mathrm{f}^{\sim}$ loor insulation - F0) and for W1SP1 window solution (double glazing with exterior solar protection).

Figure 10 presents the discomfort indicators $\left(\mathrm{DI}_{20}\right.$ and $\% \mathrm{TD}_{20}$ ) and Figure 11 presents the EC for a West-sided Brandão “school.

The city with the higher thermal discomfort is Bragança, followed by Braga, Coimbra, Porto and Lisboa.

There is an important reduction of the thermal discomfort from $\mathrm{H} 1$ to $\mathrm{H} 2$ and from $\mathrm{H} 2$ to $\mathrm{H} 3$ heating strategy. However, in Bragança there is always an important discomfort, even considering the stronger heating strategy.

The roof insulation thickness has an important role from R0 to R5 but the investment in stronger solutions does not represent a relevant reduction in thermal discomfort or in energy consumption in any location.

For a $9 \mathrm{~h}$ heating strategy, and considering the R5 roof insulation thickness, the discomfort during the occupied hours is below $40 \%$ of the time in Coimbra, Porto and Lisbon.

For a $5 \mathrm{~h}$ heating strategy, the EC is between 1500 and $2000 \mathrm{kWh}$ but the thermal discomfort increases about $1000,650,550,500$ and $400{ }^{\circ} \mathrm{C}$.hour for Bragança, Braga, Coimbra, Porto and Lisboa, when comparing with the H3 heating strategy.

For a $3 \mathrm{~h}$ heating strategy, the EC is about $1000 \mathrm{kWh}$ for all the studied cities but the \%TD is above $70 \%$ of the occupied hours for all the studied cities and roof insulation solutions.

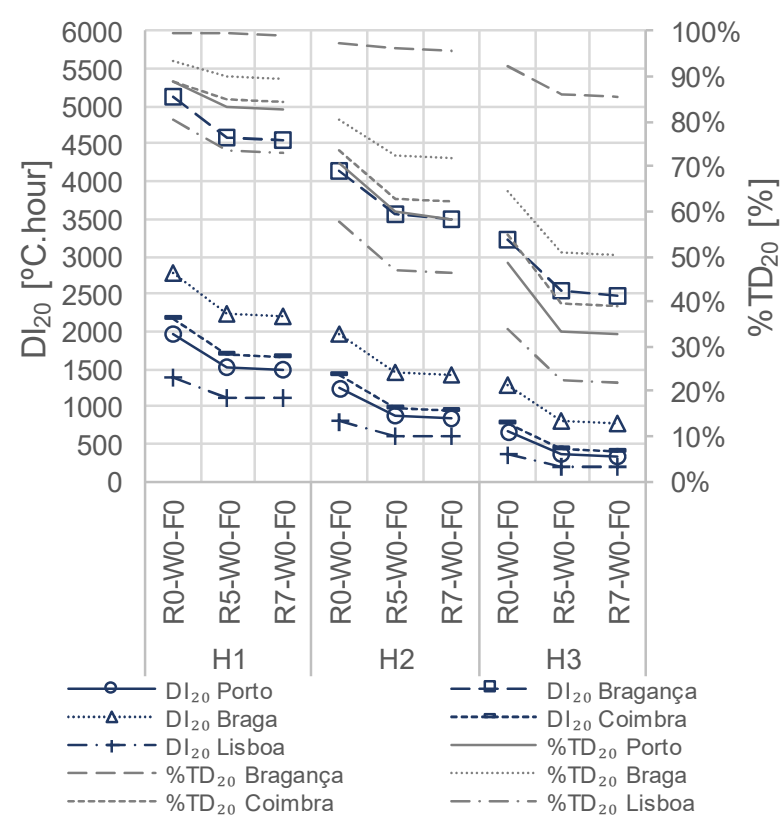

Fig. 10. Discomfort indicators ( $\mathrm{DI}_{20}$ and the \%TD) for a Westsided Brandão school for different climatic locations.

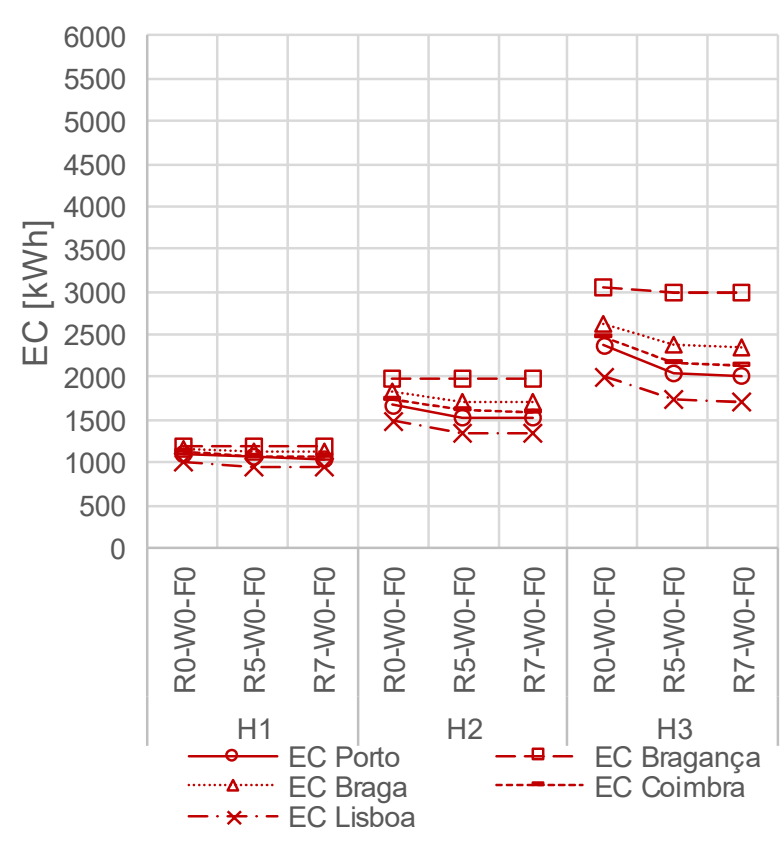

Fig. 11. Energy consumption (EC) for a West-sided Brandão school for different climatic locations.

\section{Conclusions}

Considering the Portuguese Brandão schools, the main conclusions of this paper are:

- The heating strategy has a very important role in discomfort reduction in Portuguese Brandão buildings.

- The orientation does not have an important role in the discomfort reduction.

- The roof insulation must be considered in all Portuguese Brandão schools. The first increment in roof insulation thickness (R5) has the most important role in the reduction of the discomfort $\left(\mathrm{DI}_{20}\right.$ and $\left.\% \mathrm{TD}_{20}\right)$ and of the EC. The additional increments have very low importance in the reduction of the discomfort and the EC. This conclusion was confirmed for $3 \mathrm{~h}, 5 \mathrm{~h}$ and $9 \mathrm{~h}$ heating and for all the studied cities.

- For lower heating strategies, there was an important reduction of $\mathrm{DI}_{20}$ from $\mathrm{R} 0$ to $\mathrm{R} 5$ but when the heating strategy increases, the $\mathrm{DI}_{20}$ reduction has a lower relevance (in ${ }^{\circ} \mathrm{C}$.hour) and the reduction of EC increases.

- For a 9h heating strategy, and considering the R5 roof insulation thickness, the discomfort during the occupied hours is below $40 \%$ of the time in Coimbra, Porto and Lisbon.

This work was financially supported by: Base Funding UIDB/04708/2020 of the CONSTRUCT - Instituto de I\&D em Estruturas e Construções - funded by national funds through the 
FCT/MCTES (PIDDAC). Francisca Cavaleiro Barbosa would like to thank FCT for financial support through the grant $\mathrm{PD} / \mathrm{BD} / 52658 / 2014$.

\section{References}

1. Z, Bakó-Biró, et al. Build. Environ. 2012. 48: p. 215-223.

2. T.M. Stafford, J. Environ. Econ. Manag. 2015. 70: p. 34-50.

3. R.M.S.F. Almeida and V.P. de Freitas, Energ. Buildings. 2014. 81: p. 127-40.

4. G. Rospi, et al., Energ. Buildings. 2017. 152: p. 5260.

5. L. Dias Pereira, et al., Renew. Sust. Energ. Rev. 2014. 40: p. 911-922.

6. E. Stocker, M. Tschurtschenthaler, L. Schrott, Energ. Buildings. 2015. 100: p. 20-26.

7. M.C. Katafygiotou, D.K. Serghides, Energ. Buildings. 2014. 72: p. 8-16.

8. A. Dimoudi, and P. Kostarela, Renew. Energ. 2009. 34(1): p. 289-296.

9. Agencia Estatal de Meteorología, Ministerio de Medio Ambiente y Medio Rural y Marino, and Instituto de Meteorologia de Portugal, Iberian Climate Atlas - Air temperature and precipitation (1971-2000). 2011.

10. R. Becker, I. Goldberger, and M. Paciuk, Build. Environ. 2007. 42(9): p. 3261-3276.

11. R.M.S.F. Almeida, et al., J. Perform. Constr. Fac. 2014.

12. A. Alegre, High and Technical Schools. 2010, Lisboa: Parque Escolar.

13. Instituto da Construção (IC) and Laboratório de Física das Construções (LFC), Consultancy report of a Basic School. 2009, Instituto da Construção: Porto.

14. EVO - Efficiency Valuation Organization, International Performance Measurement and Verification Protocol - Concepts and Options for Determining Energy and Water Savings (Volume 1), EVO - Efficiency Valuation Organization, Editor. 2012.

15. E. Barreira, et al., Sustain. Cities. Soc. 2017. 32: p. 397-410. 